

\title{
CLIMATE CHANGE AND FOOD SECURITY: THE ROLE OF
} BIOTECHNOLOGY

\author{
Quaye $\mathrm{W}^{1^{*}}$, Yawson RM ${ }^{1}$, Ayeh $\mathrm{ES}^{1}$ and I Yawson ${ }^{1}$
}

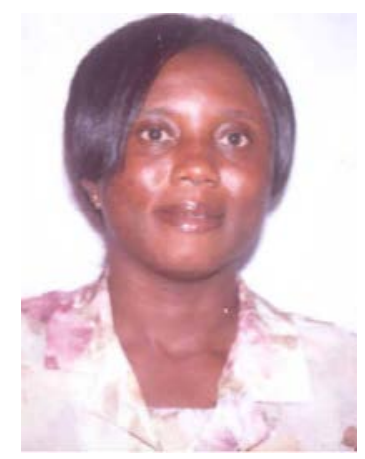

Wilhemina Quaye

*Corresponding author email: quayewilhemina@yahoo.com

${ }^{1}$ Food Research Institute (CSIR) Box M20, Accra, Ghana 


\section{ABSTRACT}

Several climate change related factors including temperature increases, changes in rainfall patterns and outbreak of pests and diseases negatively affect agricultural productivity and food security. Climate change effects significantly increase production risk and rural vulnerability, particularly in regions that already suffer from chronic soil and water resource scarcity or high exposure to climatic extremes, such as droughts and flooding. The effects of climate change on agriculture may depend not only on changing climate conditions, but also on the agricultural sector's ability to adapt through changes in technology and demand for food. Significant proportions of the growing populations in developing countries derive their livelihoods from agriculture and are, therefore, vulnerable to climate change effects. The task of eradicating extreme poverty and hunger by 2015, as per Millennium Development Goals, will require both regional and global research efforts and concrete actions among which biotechnology adoption plays a key role. Advances in biotechnology can lead to cutting-edge technologies in agriculture. However, sub-Saharan Africa faces an uphill task with regard to the adoption and use of agricultural biotechnology. The potential to improve the livelihoods of resource-poor farmers is a strong incentive to meet the challenge. This paper reviews research work on climate change in relation to increasing food insecurity situation in sub-Saharan Africa (SSA), and the significance of plant biotechnology in reversing the disturbing food insecurity trends on the continent. To move plant biotechnology forward, the paper recommends that African countries institutionalize effective bio-safety regulatory frameworks, and commit resources to capacity building and provision of infrastructure for biotechnology development. Funding of Genetically Modified Organism (GMO) related research into tropical and sub-tropical staple foods, suitable for the needs of small-scale farmers in SSA countries, is strongly recommended. There is also the need for researchers to engage in effective education and communication with the general public so as to enhance adoption of biotechnological products in Africa.

Key words: Climate, Change, Food, Security, Biotechnology 


\section{INTRODUCTION}

Food security is the state achieved when food systems operate such that "'all people, at all times, have physical and economic access to sufficient, safe and nutritious food to meet their dietary needs and food preferences for an active and healthy life" [1]. Growing world's population, increasing demand for healthy and culturally accepted food, soaring food prices and global environmental change challenges are negatively affecting food security globally and more severely in sub-Saharan Africa. The Global Hunger Index remains high for sub-Saharan Africa [2, 3, 4]. The continuing decline in food production will have to be reversed if current trends in food insecurity, poverty, and social and political instability are to be averted [5]. Area expansion and irrigation are estimated to account for $45 \%$ of the increase expected while the remainder $55 \%$ will have to come from intensification of production from land under cultivation [6].

According to Adu-Dapaah et al. [7], causes of food insecurity in sub-Saharan Africa include low agricultural productivity coupled with policy, institutional and technological challenges, high seasonal and year-to-year variability which is often linked to insufficient water for crop and livestock production. Other causes of food insecurity include limited off-farm employment opportunities and inadequate incomes in both rural and urban areas. The most rapid increase in chronic hunger experienced in recent years occurred between 2003-05 and 2007. In Ghana, about 28\% of the population live below the national poverty line [8] with high prevalence of child malnutrition, 30\% stunted, 21\% underweight and 5.4\% wasted [9]. FAO's provisional estimates show that in 2007, 75 million more people were added to the total number of undernourished relative to 2003-05.

While several factors are responsible, high food prices are driving millions of people into food insecurity, worsening the conditions for many who are already foodinsecure and threatening long-term global food security. The task of reducing the number of hungry people (as per Millennium Development Goals) will require both regional and global efforts among which biotechnology adoption could play a crucial role.

\section{DISCUSSIONS}

\section{Effect of Climate Change on Food Security}

Food security and global environmental change are interrelated and there is growing concern that while global environmental change complicates achievement of food security, increasing demand for food further degrades the environment $[10,11,12,13$, $14,15]$. Climate change may affect food systems in several ways, ranging from direct effects on crop and livestock production to changes in markets and food prices [16]. Potential effects of changes in climate on crop yields have been assessed by researchers $[17,18,19,20]$. Climate change and other global environmental changes such as changes in water availability, land cover, altered nitrogen availability and cycling (all strongly influenced by human activities), have increased concerns about achieving food security especially for poor people [21].

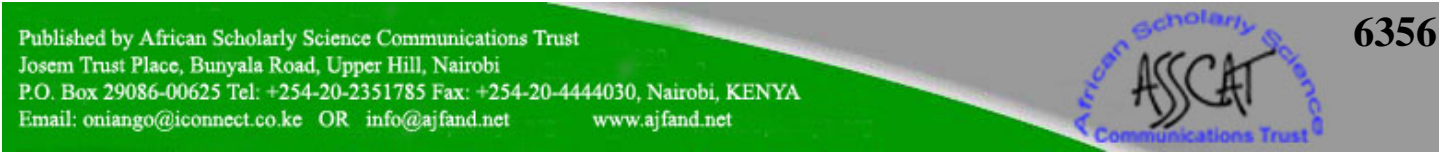


Climate change and its potential implications for agricultural water use creates increasing uncertainty for planning. It can significantly increase production risk and rural vulnerability, particularly in regions that already suffer from chronic soil and water resource scarcity or high exposure to climatic extremes, such as droughts and flooding. All of these can lead to poverty and hunger [22]. The effects of climate change on agriculture may depend not only on changing climate conditions, but also on the agricultural sector's ability to adapt through changes in technology and demand for food, coupled with management of water availability, soil quality, and crop selection [23]. Adapting to climate change will require on-going review of its impact on population growth, land and water use, the effectiveness of water demand-andsupply programs, and the capacity of emerging technologies to deal with challenges. Not only is agriculture likely to be one of the victims of climate change, it is also a contributor to the problem because of its own greenhouse gas emissions [24] as already mentioned. Water availability is expected to be highly sensitive to climate change. Changes in rainfall can affect soil erosion rates and soil moisture, both of which are important for crop yields. The United Nations' Intergovernmental Panel on Climate Change predicts that while precipitation will increase in high latitudes, it will decrease in most subtropical land regions - by as much as 20 percent in some areas [23]. The enduring changes in climate, water supply, and soil moisture could adversely affect crop production in Africa

Several factors directly connect climate change and agricultural productivity. These include average temperature increases, changes in rainfall amount and patterns, and the potential increase for more variable or extreme climatic events. Agriculture in developing countries is expected to be more vulnerable to climate change than industrialized countries, especially in sub-Saharan Africa, due to limited resources for adaptation [25]. Agricultural productivity in Africa is likely to suffer severe losses because of high temperature, severe drought, flood conditions, and soil degradation. Food security in Africa would be under tremendous threat. Irrespective of whether climate change will cause more frequent or more intense extreme events, it is apparent that many aspects of African economies are still sensitive to climatic hazards. Recent war games and intelligence studies concluded that over the next 20 to 30 years, vulnerable regions, particularly sub-Saharan Africa, the Middle East and South and South east Asia, will face the prospect of food shortages, water crises and catastrophic flooding [26]. Such climate-induced crises could topple governments, feed terrorist movements or destabilize entire regions.

Although $60-70 \%$ of the African population depends on agriculture for their livelihoods, agriculture in African is highly dependent on rainfall. Only about $4 \%$ of cropped land has access to irrigation. About 33\% and 25\% of cropped land are subjected to moderate drought and severe drought, respectively [27]. The situation is becoming more threatening with climate change effects and soaring food prices globally, which makes food importation extremely difficult. Climate change will add a further dimension to the challenge of ensuring food security for all, with the poor in sub-Sahara Africa most vulnerable because of their restricted options for coping. The damage inflicted on the environment is becoming increasingly evident. This includes arable lands lost to erosion, salinity, desertification, deforestation, loss of biodiversity

Published by African Scholarly Science Communications Trust
Josem Trust Place, Bunyala Road, Upper Hill, Nairobi
P.O. Box 29086-00625 Tel: +254-20-2351785 Fax: +254-20-4444030, Nairobi, KENYA
Email: oniango@iconnect.co.ke OR info@ajfand.net $\quad$ www.ajfand.net


and emerging water scarcity [28]. This situation will be significantly exacerbated by climate change, as well as by the increase in extreme weather events and climate variability. Work done by Brown and Funk [29] indicates that heat waves and heavy precipitation events will continue to become more frequent and future tropical cyclones will also become more intense. Droughts and water scarcity diminish dietary diversity and reduce overall food consumption and this may lead to malnutrition. The risk of flooding may increase, from both sea-level rise and increased heavy precipitation in coastal areas. This is likely to result in an increase in the number of people exposed to diarrhoea and other infectious diseases, thus lowering their capacity to utilise food effectively. Thus, food insecurity is likely to increase under climate change, unless early warning systems and biotechnologies are used more effectively.

Africa will have to pursue biotechnology applications that reduce waste from food and animal production, by altering animal metabolic processes to improve the environmental impact of animal waste management and disposal. These environmental benefits may also promote greater acceptance of biotechnology in animal and food production [30]. As climate change alters the geographic distribution of water and soil nutrients, changes in regional climate patterns caused by long-term global warming will affect the potential range of many infectious diseases. The climates of some regions will become more suitable to transmit disease agents. Human behavioral adaptations and food interventions through the use of biotechnology can mitigate many adverse impacts. Another important risk of climate change is its impact on the evolution and emergence of infectious disease agents. Ecosystem instabilities brought about by climate change and stresses, such as land-use changes, species dislocation, and increasing global trade and travel, will influence the genetics of pathogenic microbes through mutation and horizontal gene transfer. This will give rise to new interactions among hosts and disease agents. Such changes foster the emergence of new infectious diseases and the need for new food products. Changes in production practices, redistribution of natural resources, and disease emergence and proliferation have demographic impacts as well.

Climate change and its interaction with the above drivers will create demand for new food products that improve mitigation of the environmental impact of animal and food production. Biotechnology application is key to creating new food products. This requires investments in basic and applied research in order to respond to climate change effects. Technologies and surveillance methodologies that rapidly detect emerging diseases are required. Research to alter animal and plant genetics to respond to changing climates, natural resource redistributions, and disease resistance are also required. Food products based on genomics, proteomics based biomarkers for effective diagnostic techniques and disease treatments, and nutrigenomics, applications to improve human nutrition need to be developed.

\section{The Role of Biotechnology in Food Security in Africa}

Biotechnology is the use of living organisms to enhance crops, fuels, medical treatments and a host of other tools that can help humans. Modern biotechnology manipulates the genes of organisms and inserts them into other organisms to acquire the desired trait. Biotechnology contributes to poverty alleviation by increasing crop productivity and income generation, particularly for resource-poor farmers, and brings

Published by African Scholarly Science Communications Trust
Josem Trust Place, Bunyala Road, Upper Hill, Nairobi
P.O. Box 29086-00625 Tel: +254-20-2351785 Fax: +254-20-4444030, Nairobi, KENYA
Email: oniango@iconnect.co.ke OR info@ajfand.net $\quad$ www.ajfand.net


about a safer environment and more sustainable agricultural development. Advances in biotechnology can lead to cutting-edge technologies in crop agriculture in the decades ahead. Plant genomics has become a rapidly developing field that is radically improving the understanding of plant biology and creating extraordinary tools to improve plant properties related to sustainable agricultural production, human and animal nutrition, and non-food uses of plant products [30]. Plant pests and pathogens are responsible for the loss of up to 15 percent of the world's potential food-crop yields [31] and even higher percentage in sub-Saharan Africa. Plant science and molecular biotechnology can solve this problem through an improved knowledge of host-pathogen interactions, the development of new diagnostic tools, and the use of genetic modification to create resistant crop-plant varieties.

The widespread adoption of plant biotechnology in major commodity crops in the United States, for example, has resulted in significant yield increases, savings for growers, and reduced pesticide use [32]. Biotechnology has boosted the amount of grain produced per acre, for example. In 2007, the additional grain resulting from increased yields of biotech crops was enough to produce an extra 366 million gallons of ethanol. This is important because arable land is limited, yet the demand for grain for both food and fuel is growing dramatically. Crop yields are expected to continue increasing, allowing farmers to produce more corn, soybeans, and other foodstuffs on the same number of acres, thus, helping to provide sufficient supplies for both food and biofuels. One way to increase food security in Africa is to promote the use of biotechnology in agriculture on the continent.

The biotechnology tools that may be used in research are tissue culture and molecular techniques. The molecular techniques are DNA fingerprinting or characterization, marker assisted selection (MAS), molecular diagnostics and genetic engineering/transformation/genetic modification. Genetic engineering (GE) is applied in the production of genetically modified crops or recombinant vaccines. Tissue culture techniques are in use in many countries for rapid multiplication of vegetative propagated plant material. Successful private companies use the tool routinely to produce bananas, pineapples, mangoes and root crops such as potato, cassava, yam, and cocoyam. However, fewer countries use biotechnology tools as one moves the ladder from tissue culture to more advanced molecular techniques such as transformation [33].

The use of "genetically modified organisms" (GMOs) has the potential to offer real benefit in agriculture, food quality, food nutrition and health [34]. GMOs are plants or animals created through the gene splicing techniques of biotechnology. Biotechnology applications have been used to control Striga in maize fields, Maruca pod borer in insect resistant cowpea and disease resistant in banana (control banana bacterial wilt). Other examples of biotechnology applications are the production of drought tolerant maize (to reduce impact of drought), nitrogen efficient rice (improve response to nitrogen), saline tolerant rice (to extend paddy production) and bio-fortified sorghum (to improve human nutrition). Biotechnology applications have also been used in mycotoxin control (to lower peanut and maize aflatoxins), tomato resistant to the yellow leaf curl virus and cassava industrialization through mechanized cassava

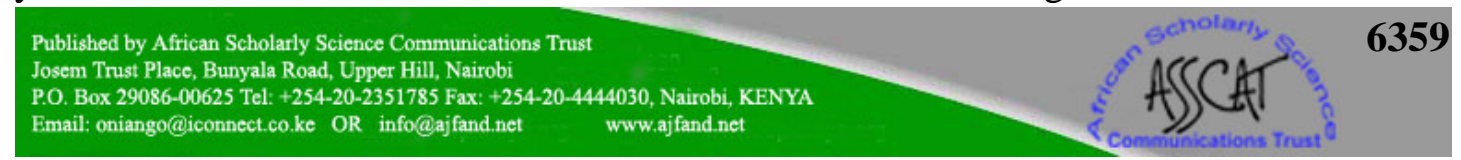


operations. In terms of crop yield, there is a wide gap between sub Sahara Africa and the rest of the world for some selected crops like banana, maize, rice and sorghum. Efficient use of biotechnology can help bridge this gap.

Africa's Consolidated Plan of Action (CPA) for Science, Technology and Innovation (2006-2010) had biotechnology, biodiversity and indigenous knowledge cluster as one of its 13 programmes. These 3 made up the African Biosciences Initiative (ABI) which created 4 bioscience network centers to drive the development of biotechnology and other biosciences in Africa.

\section{RECOMMENDATIONS}

Availability of choice: Introduction of new varieties of crops, whether GM or nonGM, may have cost implications. Problems can also arise in cases where one single monopolistic seed supplier controls the provision of seed. It is, therefore, desirable that as much as possible farmers are given opportunities to choose. To provide a genuine choice, it is important that support to the public sector be sustained so that suitable seeds (whether GM or non-GM) which can be retained by farmers with minimal yield losses are available. It is also recommended that governments in subSaharan Africa develop and implement agricultural policies that will keep private supply of seeds reasonably competitive.

Decision making processes on the use of GM crops: As much as possible, decision making process on the use of GM crops should be participatory. Local stakeholders must be well-informed and educated in order to make useful contribution to the decision making process. Farmers need to be informed about the technological potential and management requirements of GM crops. Expectations are sometimes inappropriately high, and knowledge about specialized farm management practices may be absent. It is, therefore, recommended that companies marketing GM crops in African countries use locally appropriate schemes to elicit the preferences of smallscale farmers regarding traits selected by plant breeders and also encourage local stakeholder participation in plant breeding.

Regulation of GM crops in SSA: In most SSA countries, building technical capacities and providing resources to undertake stringent biosafety evaluations and risk assessments pose a huge challenge due to financial constraints. The proliferation of diverse regulations resulting in every new GM crop being assessed for possible risks to human health and the environment in each SSA country will cause problems. Possibilities of sharing methodologies and results across countries are, therefore, recommended to be pursued. Research efforts should be well coordinated to avoid duplication. Harmonized regional policies such as established under the African Biosciences Initiative could be broadened and made to work under the umbrella of regional groupings like the ECOWAS..in full also, Southern African Development Community (SADC), the Common Market for Eastern and Southern Africa (COMESA) and the East African Community(EAC) 
Exploitation by multinationals: There are perceptions that the use of GM crops by farmers in Africa might be exploited by multinational seed industry in such a way that seed of questionable quality would be provided. This would be most unfortunate. However, it is clear that the same standards of liability need to be applied to both African countries and developed countries. Where there is clear evidence of damage attributable to the seed producer, compensation will need to be provided, regardless of whether the seed is GM or non-GM. The challenge for the public sector, especially where research is directed at agriculture in developing countries, is how to access GM technologies without infringing Intellectual Property Rights (IPRs). There is, therefore, the need for new initiatives which recognize the potential of these constraints to inhibit research into crops relevant to SSA countries. Access to plant genetic resources is critically important for the development of GM crops which are suited to the needs of SSA countries. Usually, access to such resources is governed by Material Transfer Agreements (MTAs). The perception that the recent proliferation of Material Transfer Agreements are not necessarily in the public interest is widespread.

Access to resources falling under the International Treaty on Plant Genetic Resources for Food and Agriculture is of crucial importance in the development of crops suited to SSA. It is recommended that every SSA country should ratify the treaty. Provisions should also be made to exempt users in developing countries from payments, where commercial applications arise from material covered by the MTA. Where exemptions are not appropriate, differentiation of payments should take into account the level of development of the country in question.

Current and future research: Majority of the current privately funded research on GM crops serves the interest of large-scale farmers in developed countries. Consequently, the needs of small-scale farmers in SSA countries are neglected. Crops such as rice, white maize, millet, sorghum, yams, cocoyams and cassava which provide food and income for the poor in SSA countries have been ignored by the private sector. Research on these crops will have to be supported primarily by the public sector. It is, therefore, recommended that national governments and donors should fund a major expansion of public GM-related research into tropical and subtropical staple foods, suitable for the needs of small-scale farmers in SSA countries. In determining which traits and crops need to be developed, funding bodies should consult with national and regional bodies in SSA to identify relevant priorities [5, 33]. Policy options should outline priority areas in biotechnology that are of relevance to Africa's development. Also, there is the need to identify critical capabilities needed for the development and safe use of biotechnology as well as establish appropriate regulatory measures that can advance research, commercialization, trade and consumer protection. 


\section{REFERENCES}

1. FAO. Report of the World Food Summit, FAO, Rome 1996.

2. IFPRI. Sustainable solutions for ending hunger and poverty. The Future of Small Farms for Poverty Reduction and Growth. Vision 2020 Policy Briefs, May 2007 IFPRI, Washinton DC.www.ifpri.org. Accessed 21 October 2010

3. IFPRI. The Challenges of Hunger 2008. Global Hunger Index October 2008 IFPRI, Washington DC. www.ifpri.org. Accessed 21 October 2010

4. World Bank. Global Monitoring Report 2008: MDGs and the EnvironmentAgenda for inclusive and sustainable Development http://www.odi.org.uk Accessed June 2010

5. Yawson RM and I Yawson Policy Options of Agricultural Biotechnology R\&D in ub- Saharan Africa: Key Issues and Aspects. Accepted for publication in Tailoring Biotechnologies

6. Kitch L, Koch $\mathbf{M}$ and I Sithole-Niang Crop biotechnology: A working paper for administrators and policy makers in sub-Saharan Africa, 2002. Plant Production and Protection, FAO.

7. Adu-Dapaah H, Quain MD, Thompson R, Adofo-Boateng $\mathbf{P}$ and $\mathbf{J N}$ Asafu-Agyei Harnessing Biotechnology for food security in Ghana. A paper presented at $1^{\text {st }}$ All Africa Congress on Biotechnology Held on $22^{\text {nd }}-26^{\text {th }}$ September 2008, Nairobi, Kenya.

8. World Bank World Development Indicators Database http://www.fao.org Accessed on 21 October 2010.

9. WHO. World Health Organization, Global Database on Child Growth and Malnutrition; June 2008.

10. GECAFS. Global Environmental Change and Food Systems Science Plan and Implementation Strategy. Earth System Science Partnership Report 2005. www.ihdp.unu.edu Accessed on October 28, 2010.

11. Parry ML, Rosenzweig CI, Livermore M and G Gischer Effect of Climate Change on Global food Production under SRES emissions and socioeconomics scenarios. Global Environmental Change 2004; 14:53-67.

12. Fisher $\mathbf{G}$, Shah $\mathbf{M}$ and $\mathbf{H}$ Velthuizen Climate Change and Agricultural Vulnerability. Special Report to the UN World Summit on Sustainable Development, Johannesburg 2002. 
13. Fisher G, Shah $\mathbf{M}$ and $\mathbf{H}$ Velthuizen Agriculture, Food Security and Bioenergy. In: the 21st century - The Challenges of Climate Change and Sustainable Agricultural Development, International Institute of Applied Systems (IIASA) 2008, Laxenburg , Austria.

14. Tilman D, Fargione J, Wolff $\mathbf{B}$ and D' Antonio C Forecasting Agriculturally Driven Global Environmental Change. Science, 2001; 292: 281-284

15. Rosegrant MW and SA Cline Global food security: challenges and policies. Science 2003; 302: 1917-1919.

16. Gregory PJ, Ingram JSI and M Brklacich Climate Change and Food Security. Philosophical Transaction of Royal Society 2005; 360: 2139-2148.

17. Amthor JS Effects of atmospheric $\mathrm{CO}_{2}$ concentration on wheat yield. Field Crops Research 2001; 73: 1-34.

18. Fuhrer $\mathbf{J}$ Agroecosystem responses to combinations of elevated CO2, ozone and global climate change. Agriculture Ecosystem Environment 2003; 97: 120.

19. Long SP, Ainsworth EA, Leakey ADB and PB Morgan Global food insecurity. Treatment of major food crops with elevated carbon dioxide or ozone under large-scale fully open-air conditions suggests recent models may have overestimated future yields. Philosophical Transaction of Royal Society 2005; 360: 2011-2020.

20. Jones PG and PK Thornton The potential impacts of climate change on maize production in Africa and Latin America in 2055. Global Environ. Change 2003; 13: 51-59.

21. Parry MI, Rosenzweig C, Iglesias A, Livermore M and G Gischer Effect of climate change on global food production under SRES emissions and socioeconomic scenarios. Global Environmental Change 2004; 14, 53-67.

22. FAO. Climate Change Adaptation and Mitigation: Challenges and Opportunities Security. In: The Challenges of Climate Change and Bioenergy, Proceedings of High Conference on World Food Security. Food and Agriculture Organization Rome, Italy, 2008.

23. IPCC. Climate Change: Impacts, Adaptation, and Vulnerability, In: Parry, Martin L., et al. (eds.). 2007 Cambridge University Press, Cambridge, United Kingdom. 
24. Malik MR, Yawson RM and D Hensel Destination 2025: Focus on the Future of the Food Industry. Collaboration between the BioBusiness Alliance of MN and Deloitte Consulting LLP. 2009 Available at SSRN: http://ssrn.com/abstract-1418204 Accessed on 21 October 2010.

25. USCCSP. United States Climate Change Science Program The Effects of Climate Change on Agriculture, Land Resources, Water Resources, and Biodiversity in the United States: Synthesis and Assessment Product 4.3 Report, 2008.

26. Broder JM Climate Change Seen as Threat to U.S. Security. The New York Times, 2009 August 8th Edition, New York.

27. Shah MM, Fisher $\mathbf{G}$ and $\mathbf{H}$ Velthuizen Food Security and Sustainable Agriculture. The Challenges of Climate Change in sub-Sahara Africa. International Institute for Applied Systems Analysis Laxenburg, Austria 2008.

28. FAO. The State of Food Insecurity in the World: High Food Prices and Food Insecurity -Threats and opportunities, 2008 Report.

29. Brown ME and CC Funk Food Security under Climate Change. Science 2008; 319:580-581.

30. European Commission. Plants for the Future, 2025: A European Vision for Plant Genomics and Biotechnology 2007. Directorate-General for Research, Information and Communication Unit, B-1049 Brussels.

31. Jones M Status of Biotechnology in Africa. A paper presented at $1^{\text {st }}$ All Africa Congress on Biotechnology Nairobi-Kenya, September, 22-26 2008.

32. Yawson RM and AJ Sutherland Institutionalizing Performance Management in R\&D Organizations: Key Concepts and Aspects. Journal of Social Sciences, 2010; 22:163-172.

33. Dionne NS, Mangwende T, Martin DP, Bezuidenhout M and FJ Kloppers Transgenic resistance to MSV in Maize. Plant Biotechnology Journal 2007; 5:759-767.

34. Quaye W, Yawson I, Yawson RM and IE Williams Acceptance of biotechnology and social-cultural implications in Ghana. African Journal of Biotechnology 2009 ; 8:1997-2003.

35. Yawson RM, Quaye W, Williams IE and I Yawson A Stakeholder Approach to Investigating Public Perception and Attitudes towards Agricultural Biotechnology in Ghana. Tailoring Biotechnologies 2008; 4: 55-70. 